\title{
IMPLEMENTASI NILAI-NILAI PERJUANGAN DIPONEGORO DALAM PEMBELAJARAN IPS DI SD DIPONEGORO
}

\author{
Suyanti \\ yantiramaputra@gmail.com \\ IKIP PGRI MADIUN
}

\begin{abstract}
This research is aimed to investigate: 1) Teacher's understanding about Diponegoro's value struggle in Elementary school Diponegoro, 2).the implementation of Diponegoro's Value Struggle on Social Learning 3) The barriers which are faced implementation Diponegoro's value struggle in Elementary School Diponegoro. This research used descriptive qualitative method. Results of this research are: 1) teacher's understanding about Diponegoro's value struggle is in the form of religious attitude, honesty, care and the spirit of nasionalism. 2). Diponegoro values have been inserted into learning set.3) barriers faced by teacher in implementation Diponegoro's value struggle as in Elementary School Diponegoro is the negative effect of globalization to the student and the lack of learning resources.

Keywords: Diponegoro, Social learning.
\end{abstract}

\begin{abstract}
ABSTRAK
Penelitian ini bertujuan untuk mengetahui: (1).Pemahaman guru terhadap nilai-nilai perjuangan Diponegoro di SD Diponegoro. (2). Implementasi nilai-nilai perjuangan Diponegoro dalam pembelajaran IPS .(3).Kendala-kendala yang dihadapi dalam implementasi nilai-nilai perjuangan Diponegoro di SD Diponegoro. Penelitian ini merupakan penelitian kualitatif deskriptif. Hasil penelitian ini adalah sebagai berikut: (1). Pemahaman guru terhadap nilai-nilai perjuangan Diponegoro adalah berupa sikap religius, kejujuran, peduli dan semangat kebangsaan yang tinggi. (2) Implementasi nilai-nilai perjuangan Diponegoro telah di cantumkan dalam perangkat pembelajaran.(3) kendala-kendala yang dihadapi guru dalam implementasi nilai-nilai perjuangan Diponegoro adalah kurangnya sumber belajar dan pengaruh negatif Era Globalisasi.

Kata kunci: Diponegoro, Pembelajaran IPS.
\end{abstract}


85 | Premiere Educandum, Volume 6 Nomor 1, Juni 2016, 84 - 94

\section{A. PENDAHULUAN}

Berdasarkan Undang-undang Sistem Pendidikan Nasional tahun 2003 tentang tujuan Pendidikan Nasional pasal 3 menyatakan bahwa:

Pendidikan Nasional berfungsi mengembangkan kemampuan dan membentuk watak serta peradaban bangsa yang bermartabat dalam rangka mencerdaskan kehidupan bangsa bertujuan untuk berkembangnya potensi peserta didik agar menjadi manusia yang beriman dan bertaqwa kepada Tuhan Yang Maha Esa: berakhlak mulia: sehat berilmu; cakap; kreatif mandiri dan menjadi warga Negara yang demokratis serta bertanggung jawab.

Peran akhlak dalam undangundang tersebut merupakan aspek yang penting dalam upaya untuk mendidik anak. Pelaksanaan penyelenggaraan pendidikan sebagai proses pembinaan bangsa masih sangat memprihatinkan. Dewasa ini banyak fenomena terkait soal kenakalan remaja yang melibatkan pelajar seperti perkelahian massal, school bullying, atau kekerasan yang dilakukan oleh guru terhadap peserta didik (Fatchul, 2011: 37).
Peserta didik harusnya menyadari bahwa hidup saat ini karena jasa para pahlawan bangsa yang sudah memperjuangkan kemerdekaan. Oleh karena itu guru diharapkan dapat mengajarkan, menanamkan dan menumbuhkan semangat kepahlawanan dan perlu peneladanan aktualisasi nilainilai yang dimiliki para pahlawan sehingga peserta. Salah satu sosok pahlawan yang bisa diteladani ialah Pangeran Diponegoro, beliau memiliki nilai-nilai perjuangan yang dapat memberikan inspirasi kepada siswa. Strategi dalam mengaktualisasi nilai dapat dilakukan melalui integrasi pembelajaran IPS, IPS di tingkat sekolah dasarnya bertujuan untuk mempersiapkan para peserta didik sebagai warga negara yang mempunyai pengetahuan (knowledge), ketrampilan (skill), sikap dan nilai (attidues and values) yang dapat dijadikan sebagai kemampuan untuk memecahkan masalah pribadi atau masalah sosial dan kemampuan mengambil keputusan serta berpartisipasi dalam berbagai kegiatan kemasyarakatan agar menjadi warga negara yang baik (Sapriya, 2009:12).

Berdasarkan latar belakang yang telah disampaikan tersebut peneliti 
memfokuskan penelitian ini dalam pembinaan nilai untuk perkembangan mengakaji "Implementasi Nilai-nilai kepribadian melalui pengalaman Perjuangan Diponegoro Dalam belajarnya masing-masing. Pembelajaran IPS di SD Diponegoro". Sastraprateja dalam Elmubarok Bertitik tolak dari latar Belakang seperti (2013:12) memberikan definisi telah diuraikan di atas, maka rumusan Pendidikan nilai adalah penanaman dan masalahnya dapat dikemukakan sebagai pengembangan nilai-nilai pada diri berikut: seseorang. Hal ini sejalan dengan 1. Bagaimana pemahaman guru pendapat Djahiri dalam Wiranto (2011: terhadap nilai-nilai Perjuangan 191) bahwa pendidikan nilai merupakan Pangeran Diponegoro di SD penanaman nilai-nilai untuk menangkis Diponegoro?

pengaruh nilai-nilai negatif atau yang

2. Bagaimana Implementasi nilai-nilai perjuangan pangeran Diponegoro dalam pembelajaran yang meliputi perecanaan, proses dan evaluasi di SD Diponegoro?

3. Apa saja kendala-kendala yang dihadapi guru dan cara mengatasinya dalam Implementasi nilai-nilai Perjuangan Pangeran Diponegoro di SD Diponegoro?

\section{Pendidikan Nilai}

cenderung mendorong nilai-nilai dalam artian moral yang merupakan akibat arus globalisasi.

Pendidikan nilai menurut Mulyana (2011: 119) adalah pengajaran atau bimbingan kepada peserta didik agar menyadari nilai kebenaran, kebaikan, dan keindahan, melalui proses pertimbangan nilai yang tepat dan pembiasaan bertindak yang konsisten. Pendidikan nilai Pendidikan nilai berperanan dimaksudkan untuk membantu peserta penting dalam upaya mewujudkan didik agar memahami, menyadari, dan manusia Indonesia yang utuh. mengalami nilai-nilai serta mampu Pendidikan nilai Menurut Naomi (2000: 191) merupakan proses belajar lewat pengalaman sosial alamiah masingmasing orang yang di dalamnya terdapat unsur penyampaian dan proses menempatkannya secara integral dalam kehidupan. Kirschenbum (2000: 16) menekankan beberapa nilai dasar (corevalue) yang perlu diberikan dalam pendidikan nilai yakni kepercayaan, 
87 | Premiere Educandum, Volume 6 Nomor 1, Juni 2016, 84 - 94

hormat, tanggung jawab, kepedulian,

Ilmu Pengetahuan Sosial (IPS) keadilan dan kepercayaan.

adalah salah satu mata pelajaran yang

Aspin dalam Thornberg (2008: ada di tingkat pendidikan dasar dan 52) menyatakan "value education menengah. Somantri menjelaskan refers to pedagogical practice in which pengertian IPS (2001:101) dibawah ini: young people learn values and morality "Di Indonesia, Ilmu Pengetahuan and adquire knowledge of this domain about relating to order people, together with the ability and disposition to apply the values and rules intelligently". Peryataan tersebut mengandung makna pendidikan nilai mengacu kepada Sosial (IPS) merupakan salah satu mata pelajaran yang diberikan mulai dari SD/MI/SDLB sampai SMP/MTS/SMPLB. Istilah IPS muncul pada tahun 1975-1976, yaitu pada saat penyusunan kurikulum Pendidikan PSP, praktek pendidikan dimana siswa diajak yaitu sebuah "label" untuk mata mempelajarai nilai-nilai dan moralitas pelajaran sejarah, ekonomi, geografi dan selanjutnya siswa memperoeh dan mata pelajaran sosial lainnya untuk pengetahuan (nilai-nilai dan moralitas pendidikan dasar dan menengah. untuk) berhubungan dengan orang lain, Sedangkan di luar negeri, terutama di dan bersama-sama dengan kemampuan Amerika Serikat, para pakar pendidikan dan kecenderungan menerapkan nilai- dan ilmu sosial dalam wadah National nilai dan peraturan secara tepat. Council for Social Studies (NCSS) Sudarminta (2002:456) menjelaskan Social Science Education Consurtium pendidikan nilai merupakan upaya (SSEC) sudah sejak tahun 1920-an untuk membantu peserta didik memikirkan maslah pendidikan ilmumengenal, menyadari pentingnya, dan ilmu sosial pada tingkat pendidikan menghayati nilai-nilai yang pantas dan dasar menengah ini”.

semestinya dijadikan panduan bagi Ilmu Pengetahuan Sosial sikap dan perilaku manusia, baik secara perorangan maupun bersama-sama dalam masyarakat.

\section{Pembelajaran IPS}

merupakan penyederhanaan dari konsep Ilmu-ilmu Sosial yang ada. M.N. Somantri (2001: 74), mengemukakan bahwa pendidikan IPS adalah suatu penyederhanaan disiplin ilmu-ilmu 
sosial, ideologi negara dan disiplin ilmu lainnya serta masalah-masalah sosial terkait, yang diorganisasikan dan disajikan secara ilmiah dan psikologis untuk tujuan pendidikan pada tingkat dasar dan menengah.

Adanya pembedaan definisi PIPS di Indonesia ini berimplikasi bahwa PIPS dapat dibedakan atas dua, yakni PIPS sebagai mata pelajaran dan PIPS sebagai kajian akademik. PIPS sebagai mata pelajaran terdapat dalam kurikulum sekolah mulai tingkat sekolah dasar (SD) hingga menengah (SMP/MTs dan SMA/MA/SMK). PIPS pada kurikulum sekolah (satuan pendidikan), pada hakikatnya merupakan mata pelajaran wajib sebagaimana dinyatakan dalam Undang-undang Nomor 20 tahun 2003 tentang Sistem Pendidikan Nasional Pasal 39 (Sapriya, 2014: 12). Dimyati (1989: 90) menjelaskan bahwa secara umum tujuan pengajaran ilmu-ilmu sosial, khususnya dalam arti social studies atau IPS, adalah meliputi tiga segi pendidikan seperti humanisticeducation, social civic education, dan intellectual education (pendidikan kemanusian, kemasyarakatan kenegaraan dan pendidikan inteletual).
Dari uraian di atas dapat disimpulkan bahwa IPS adalah mata pelajaran pada jenjang pendidikan di tingkat sekolah dasar yang dikembangkan secara terintegrasi dengan mengambil konsep-konsep esensial dari ilmu-ilmu sosial dan humaniora. IPS terus dikembangkan untuk kepentingan tujuan pendidikan. Dengan adanya mata pelajaran IPS di sekolah diharapkan siswa dapat mengerti dan mengamalkan makna pelajaran IPS sehingga memiliki karakter dan menjadi warga negara yang baik.

\section{B. METODE PENELITIAN}

Penelitian ini menggunakan penelitian kualitatif dengan pendekatan diskriptif dan jenis penelitian studi kasus. Sumber data yang diperoleh dari informan yaitu kepala sekolah, guru, dan peserta didik yang dilakukan melalui wawancara mendalam, mengumpulkan berbagai peristiwa atau aktivitas yang dilakukan, pengambilan dokumen serta tambahan angket peserta didik di SD Diponegoro. Tehnik pengumpulan data dalam penelitian ini menggunakan tehnik wawancara, observasi, dokumentasi. Tehnik 
Wawancara digunakan untuk Abidin (2012) menjelaskan dalam menyaring data yang berkaitan dengan penelitiannya, nilai Diponegoro yang penanaman nilai-nilai perjuangan perlu diwariskan dalam penelitiannya Diponegoro. Observasi digunakan adalah religiusitas, kejujuran, untuk memperoleh data mengenai keberanian, dan kepedulian. pelaksanaan Implementasi nilai-nilai Pemahaman tentang nilai-nilai perjuangan Diponegoro, dokumentasi perjuangan Diponegoro juga digunakan untuk mengetahui gambaran direalisasikan melalui tujuan, visi dan objek yang di teliti serta angket misi sekolah. Tugas dari sekolah ialah disebarkan kepada peserta didik. Tehnik membina visi dan misi yang bekaitan sampling menggunakan purposive dengan nilai-nilai perjuangan sampling, dan validitas data yang Diponegoro tersebut. Wibowo digunakan dalam penelitian ini adalah (2013:119) menyatakan bahwa Kepala triangulasi metode dan triangulasi sekolah memiliki peran yang kuat dalam sumber. Analisis data menggunakan mengkoordinasikan, menggerakkan, analisis interaktif yaitu reduksi data, dan menyerasian semua sumber daya sajian data, dan penarikan pendidikan yang tersedia. Kepala simpulan/verifikasi.

\section{PEMBAHASAN}

1. Pemahaman guru terhadap Nilainilai perjuangan Diponegoro di SMP Diponegoro.

Nilai-nilai perjuangan Diponegoro dapat memberikan inspirasi kepada siswa. Pemahaman guru terhadap nilai-nilai perjuangan Diponegoro antara lain beliau adalah seorang pemimpin muslim yang religius, jujur, peduli dan mempunyai semangat kebangsaan yang tinggi. sekolah merupakan salah satu faktor yang dapat mendorong sekolah untuk mewujudkan visi, misi, tujuan, dan sasaran sekolahnya melalui programprogram yang dilaksanakan secara terencana.

2. Implementasi nilai-nilai perjuangan pangeran Diponegoro dalam pembelajaran yang meliputi perecanaan, proses dan evaluasi di SD Diponegoro

Implementasi nilai-nilai perjuangan pangeran Diponegoro pada 
umumnya bisa diintegrasikan pada pembelajaran), c) penilaian. Hal ini di semua mata pelajaran yang ada sejalan dengan penelitian Anik Ghufron disekolah, salah satunya pada mata (2010) yang menyatakan bahwa, dalam pelajaran IPS. Proses Implementasi pengintegrasian nilai-nilai bangsa nilai-nilai perjuangan Pangeran meliputi tiga tahap yakni pendahuluan, Diponegoro pada mata pelajaran IPS inti, dan penutup, dan dalam proses bahwasannya dilakukan pada pelaksanaannya diperlukan dukungan pembelajaran di dalam kelas. Saripudin (1989: 38), bidang studi Ilmu Pengetahuan Sosial merupakan salah satu unsur kurikulum pendidikan yang secara formal dan material menjabarkan esensi Tujuan Pendidikan Nasional. Untuk itu, merupakan suatu keharusan bagi bidang studi untuk menjabarkan tujuan tersebut dalam wawasan dan perspektif keilmuan sosial. Hal ini di dukung pendapat Dimyati (1989: 90), menyatakan bahwa secara umum tujuan pengajaran ilmu-ilmu sosial, khususnya dalam arti social studies atau IPS, adalah meliputi tiga segi pendidikan seperti humanisticeducation, social civic education, dan intellectual education (pendidikan kemanusian, kemasyarakatan kenegaraan dan pendidikan inteletual).

Proses Implementasi nilai-nilai perjuangan Diponegoro dalam pembelajaran IPS meliputi: a) perencanaan, b) pelaksanaan pembelajaran (tahap-tahap dari pihak sekolah, guru, orang tua, dan siswa. Alokasi Waktu 4x35 menit (2x pertemuan), Kelas VII. Metode yang digunakan yaitu dengan metode kooperatif tipe Jigsaw. penggunaan metode kooperatif dalam hal ini untuk bisa menyesuaikan dengan jumlah siswa, materi pembelajaran dan alokasi waktu. Materi pelajaran berperan penting dalam menggali nilai-nilai karakter perjuangan Diponegoro. Hal ini Sejalan dengan penelitian Sudarmin (2014) bahwa penelitian tersebut memberikan gambaran bahwa model Jigsaw tidak hanya mampu mengembangkan capaian akademik, tetapi non akademik, seperti saling menghargai saling peduli satu sama lain sehingga meningkatkan hubungan interpersonal diantara mereka

Penggunaan media sudah maksimal yaitu mengunakan laptop, LCD, pemutaran video. Sumber belajar dalam penggunaannya sangat kurang 
belum tersediannya buku pegangan murid menjadi kendala tersendiri. Peserta didik hanya menggunakan modul yang dibuat oleh guru untuk menganggulangi kurangnya bacaan siswa. Implementasi nilai-nilai perjuangan Diponegoro kepada peserta didik menggunakan media juga sangat efektif, terlihat peserta didik fokus terhadap pembelajaran. Hal ini relevan dengan pendapat Soko (2011) bahwa penanaman nilai-nilai karakter pada siswa tidak bisa dilakukan dengan metode inkulkasi dan keteladanan, namun juga bisa diajarkan melalui media pembelajaran. Upaya menanamkan nilai-nilai karakter melalui media membuat siswa siswa tidak merasa diatur dan didikte. pembelajaran menggunakan contoh dan cerita untuk memunculkan nilai-nilai menceritakan kisah hidup orang yang berhasil, dan refleksi, siswa dapat mengajari nilai-nilai karakter dan memaknai dengan baik. Penilaian yang dilakukan melalui dalam tiga aspek yaitu aspek kognitif, afektif dan psikomotorik. Penilaian aspek kognitif menggunakan tes, untuk aspek afektif dan psikomotorik menggunakan lembar observasi
3. Kendala dalam penanaman nilainilai karakter perjuangan Diponegoro dan cara mengatasinya dalam pembelajaran IPS

Kendala dalam implementasi nilai-nilai perjuangan pangeran Diponegoro di SD Diponegoro yang pertama adalah kurangnya sumber buku-buku bacaan dalam pembelajaran IPS. Kelengkapan sarana dan prasarana dalam proses pembelajaran tidak menentukan jaminan kegiatan kondisi belajar mengajar yang baik, tetapi disinilah muncul untuk mengelola sarana dan prasarana bagi terselenggaranya kegiatan belajar mengajar yang berjalan dengan efektif. Pengelolaan sarana dan prasarana dalam satuan pendidikan harus dilaksanakan. Dimyadi dan Mudjono (2006:249) Sarana pembelajaran meliputi buku pembelajaran, buku bacaan, alat dan fasilitas laboratorium sekolah, dan berbagai media pengajaran yang lain. Prasarana pembelajaran meliputi gedung sekolah, ruang belajar, lapangan olahraga, ruang ibadah, ruang kesenian, peralatan olahraga dan sebagainya. Sarana dan prasarana pembelajaran yang lengkap merupakan kondisi yang 
baik sehingga menciptakan proses Para siswa ada sebagian tidak dapat belajar yang berhasil baik pula. Dalam menyaring mana yang baik dan mana hal ini untuk mengatasi kurangnya yang tidak baik. Upaya yang dilakukan ketersedian sumber bacaan guru IPS dalam mengatasi dampak negatif arus membuat modul pembelajaran dan globalisasi dilakukan dengan sumber atau referensi penunjang untuk meningkatkan pengawasan peran mempermudah siswa dalam komite sekolah dan meningkatkan memahamai materi pelajaran IPS yang intensitas hubungan wali murid dengan diberikan oleh guru. Guru dituntut wali kelas. Peran komite sekolah untuk juga kreatif dalam menyediakan ditingkatkan dengan mengadakan sumber bacaan demi terselengaranya pertemuan rutin sebulan sekali untuk proses pembelajaran yang efektif. Dewi membahas dan mengevaluasi (2013) menjelaskan dalam proses pelaksanaan kegiatan sekolah. Mulyasa pelaksanaan guru menghadapi (2008: 26) menyatakan bahwa kesulitan-kesulitan dalam menemukan diperlukan kerjasama dalam membina sumber atau referensi bacaan, akhirnya dan membentuk perilaku-perilaku guru membuat solusi mengatasi sesuai dengan nilai-nilai yang masalah dengan cara mencari sumber ditanamkan, diajarkan dan penunjang yang lain dan referensi lain diteladankan. Oleh sebab itu sehingga pembelajaran akan lebih Implementasi nilai-nilai perjuangan bermakna. pangeran Diponegoro harus mendapat

Kendala yang kedua adalah dukungan dari pihak sekolah maupun mengenai pengaruh negatif arus dari orang tua wali murid para siswa. globalisasi. Abad 21 yang ditandai dengan arus globalisasi serta ditunjang tekhnologi informansi, komunikasi, dan transparansi merupakan tantangan yang telah mengubah aspek kehidupan masyarakat begitu cepat. Dampak arus globalisasi membawa pengaruh terhadap sikap, perilaku dan moral.

\section{Simpulan}

1. Nilai-nilai karakter perjuangan pangeran Diponegoro dianggap penting sebagai semangat pembangunan adalah Kereligiusan, Kejujuran, kepedulian, semangat kebangsaan. Nilai-nilai karakter 
93 | Premiere Educandum, Volume 6 Nomor 1, Juni 2016, 84 - 94

perjuangan Pangeran Diponegoro

dianggap penting untuk diteruskan

sebagai semangat pembangunan

untuk masa kini maupun untuk masa

yang akan datang.

2. Implementasi nilai-nilai perjuangan

Diponegoro dalam pembelajaran IPS di SD Diponegoro cukup baik. Perangkat pembelajaran telah mencantumkan nilai- nilai yang akan diimplementasikan dalam diri siswa ketika proses belajar mengajar berlangsung salah satunya nilai-nilai perjuangan Diponegoro, yang meliputi tiga kegiatan yaitu: tahap perencanaan, tahap pelaksanaan, dan tahap evaluasi.

3. Kendala yang dialami guru dalam penanaman nilai-nilai perjuangan Diponegoro di SD Diponegoro yaitu kurangnya sumber bacaan penunjang dalam pembelajaran cara mengatasinya guru membuat modul sebagai penunjang sumber dalam pembelajaran. pengaruh negatif dampak Era globalisasi. Cara mengatasinya yaitu dilakukan dengan meningkatkan pengawasan peran komite sekolah dan meningkatkan intensitas hubungan wali murid dengan wali kelas.

\section{DAFTAR PUSTAKA}

Abidin, Zaenal. Pendidikan Karakter Diponegoro. Seminar Nasional Psikologi Islami. Surakarta 21 April 2012.

Dimyati, $\quad$ Muhammad. 1989. Pengajaran Ilmu-ilmu Sosial di Sekolah: Bagian Integral Sitem Ilmu Pengetahuan. Jakarta: Depdikbud.

Dewi, Kusmiyati Tini. 2013. Implementasi Nilai-nilai Patriotisme Siswa Melalui Kajian Biografi Raden Haji Perwatasari dalam Pembelajaran Sejarah (Penelitian Naturalistik Inquiri SMAN 1 Cianjur). Tesis Universitas pendidikan Indonesia.

Elmobarok. 2013. Membumikan Pendidikan Nilai. Bandung: Alfabeta.

Gufron, Anik. 2010. "Integrasi Nilainilai Karakter Bangsa pada Keiatan Pembelajaran". Jurnal Ilmiah Pendidikan (Nomor ISSN; 0216-1370).

Intan, Naomi. 2000. Menggugat Pendidikan Fundamentalis, Konservatif, Liberal, Anarkis. Yogyakarta: Penerbit Pustaka Pelajar.

Kirchenburn. 2000. From Values Clarification to Character Education a personal journey. Jurnal of Humanist Consuling Education \& Development. Alexander Vol 39 ISSI: P4(14 Pages).

Mudjiono, Dimyati. 2006. Belajar dan Pembelajaran. Jakarta: Rineka Cipta. 
Mu'in, Fatchul. 2011. Pendidikan Karakter: Kontruksi Teoritik \& Praktik. Yogyakarta: Ar-Ruzz Media.

Mulyana. 2011. Mengartikulasikan Pendidikan Nilai. Bandung; Alfabeta.

Mulyasa. 2002. Kurikulum Berbasis Kompetensi.

Bandung; Rosdakarya.

Sudarmini, Luh. 2014. Pengaruh Pembelajaran Kooperatif Tipe Jigsaw Terhadap Motivasi Belajar dan Hasil Belajar Siswa Kelas V Seklah Dasar Gugus IV Jimbaran Kuta Selatan.

Soko, Imelda Paulina. 2010. Pengaruh Pemanfaatan Media Flash Berbasis Karakter terhadap Keefektifan Pembelajaran IPA. TESIS: Universitas Negeri Yogyakarta.

Sapriya. 2014. Pendidikan IPS: Konsep dan Pembelajaran. Bandung: PT Rosdakarya.

Saripudin, Urip. 1989. Konsep Dan Masalah Pengajaran Ilmu Sosial Di Sekolah Menengah. Jakarta: LPTK.

Sudarmina. 2002. Pendidikan dan Pembetukan watak yang bail, dalam pendidikan untuk masyarakat Indonesia baru, 70 tahun Prof H.A.R. Tilaar, M. Sc Ed. Jakarta: PT Grasindo.

Soemantri. 2001. Menggagas Pemahaman Pendidikan IPS. Bandung: PT Rosda Karya.

Thornberg, Robert. (November 2008). Values Education as The Daily fostering of school rules. Research in education.
Manchester. Vol 80, ISS 1 p. 52 (11 pages).

Widiastuti, Tri. 2007. Penanaman nilainilai Iman dan Taqwa untuk Pembinaan Moral Melalui Pembelajaran IPS di SMP Negeri 2 Bawang. TESIS Universitas Negeri Yogyakarta.

Wibowo. 2012. Pendidikan Karakter: Strategi Membangun Karakter Bangsa Berperadaban. Yogyakarta: Pustaka Pelajar.

Wirantho, Sapto Aji. 2011. Pendidikan Nilai dalam Menghadapi Tantangan Perubahan ada peserta Didik SMA. Jurnal Teknologi Pendidikan, Vol 13 No 3.

Undang-undang Nomor 20 Tahun 2003 Tentang Sistem Pendidikan Nasional pasal 3. Jakarta: Eka Jaya.

Zuriah. 2008. Pendidikan Moral Dan Budi Pekerti Dalam Perspektif Perubahan. Jakarta: Bumi Aksara. 